\section{Remote and Close}

\section{Range Sensing for the}

Automatic Identification

and Characterization of

Archaeological Looting. The

Case of Peru

\author{
NICOLA MASINI (1)
}

ROSA LASAPONARA (D)

*Author affiliations can be found in the back matter of this article

\begin{abstract}
Looting is the major source of artefacts for the antiquities market. Specific measures are needed to fight the whole chain of the illicit activities undertaken by criminal organizations (from the excavation to the selling of the artefacts), and they should be devised for each phase of such illegal activities. The development and use of appropriate technologies for the identification of the most 'vulnerable' sites, and the timely detection and automatic quantification of the extension of the looted areas are crucial steps for setting up a monitoring system working also for remote and inaccessible archaeological areas, often in regions affected by armed conflicts or characterized by flight restrictions. In this context, Earth Observation (EO) technologies can provide reliable information: (i) to quantify the looting phenomenon even if it is on an 'industrial scale' over large areas, and (ii) to set up a systematic monitoring tool to trace the illicit trade in antiquities.
\end{abstract}

In this paper, an improvement of the Archaeological Looting Feature Extraction Approach (ALFEA) -developed by the same authors in 2018- is proposed to further improve the ability in the automatic identification and extraction of looting features for heterogeneous desert landscapes, characterized not only by looting patterns but also by archaeological micro-relief and emerging remains, as well as by natural geomorphological features and the presence of structures and dirt pathways, which exhibit a similar spectral behavior but dimensions, morphology, and/or geometric patterns different from those linked to looting. The improvement of ALFEA (ALFEA-I) was applied in significant test areas considered among the most important archaeological sites in Peru, (i) Pachacamac close to Lima, and (ii) Ventarron in the Lambayeque region Northern Peru. The first site is characterized by past clandestine excavations and looting is difficult to recognize both in situ and from satellite image; the second site is affected by more recent archaeological disturbances due to grave robberies, easier to identify from remote sensing data.

The original ALFEA -composed of the sequential integration of spatial autocorrelation statistics, unsupervised classification, and segmentation- has been herein refined by adding a processing step based on multi-threshold parameters of segmentation, thus improving the performance in terms of extraction capability of looting features in case of heterogeneous areas. The integration of satellite based data processing with unmanned aerial vehicle (UAV) based close range acquisitions has proved to be effective in enhancing the visibility of old looting features, crucial for the validation of ALFEA-I.
RESEARCH ARTICLE

\section{] $\mathrm{u}[$ ubiquity press}

CORRESPONDING AUTHOR:

\section{Nicola Masini}

Institute of Heritage Science, CNR-ISPC(Italy); C. da S. Loya, 85050 Tito Scalo, Potenza, Italy

nicola.masini@cnr.it

KEYWORDS:

ALFEA-I; archaeological

looting; spatial

autocorrelation; automatic classification and mapping; Peru

TO CITE THIS ARTICLE: Masini, N and Lasaponara, R. 2021. Remote and Close Range Sensing for the Automatic Identification and Characterization of Archaeological Looting. The Case of Peru. Journal of Computer Applications in Archaeology, 4(1), 126-144. DOI: https://doi.org/10.5334/ jcaa. 73 


\section{INTRODUCTION AND RESEARCH MOTIVATION \\ 1.1 PREMISE}

Archaeological looting, defined as the illicit removal of artefacts from a site of archaeological interest, is a phenomenon of global proportions that adversely impacts Cultural Heritage $(\mathrm{CH})$, causing irreversible damages. In fact, along with the damage and loss of artefact, illegal archaeological excavations cause the irreversible destruction of stratigraphic data and the 'cultural context' that are lost forever and cannot be restored any more. Some archaeological sites have been completely 'erased' and today they are only known from their looted antiquities present on the market or in collections (Forrest 2010; UNESCO 1970).

Looting is the major source of artefacts for the antiquities market, and, therefore, the illegal excavations are only the first step of several forms of criminal activities linked with the illicit trade of the stolen artefacts, which includes several forms of criminal figures, as thieves, fences, launderers, and traffickers also based on modern tools as e-commerce. Specific measures are needed to limit these illicit activities and they should be devised to halt each phase of these illegal activities. This consideration must inspire and strongly motivate all efforts aimed at the contrasting, mitigating, and monitoring of the phenomenon, with all the implications that these actions may have in the raising of awareness along with information and dissemination among citizens, particularly the younger generations. The development and use of appropriate technologies for the identification of the most 'vulnerable' sites, and the timely detection (and the automatic quantification of the extension) of the looted areas are a crucial step for setting an in situ monitoring system especially for remote and inaccessible archaeological areas.

Looting is one of the main risk factors that affect the archaeological heritage all over the world; it is much more intense, frequent, and destructive in countries, as Southern America (Higueras 2008; Proulx 2013; Yates 2015) and Middle East (Stone 2008; Casana 2015), where archaeological sites are located in remote areas, strongly affected by the phenomenon since centuries. With this respect, Peru can be considered as an emblematic area to observe the phenomenon, suitable not only to understand the socio-economic, cultural, and anthropological implications connected with looting but also to devise effective contrasting strategies, interventions, and methods to be reapplied in other regions of the world (Lasaponara \& Masini 2018).

Although in 1882 Peru was one of the first countries of the American continent to approve and adopt a legislation for the protection of cultural heritage, it was - and still is today - among the countries most affected by devastation of archaeological sites and landscapes (Batievsky \& Velarde 2006). In the past, the phenomenon of the huaqueo - archaeological looting - was deeply based on a close relationship between huaqueros - who dug clandestinely for earning a living - and those who managed a rich and well-organized business with the connivance of museums, auction houses, and private collectors (Alva 2001; Gerdau-Radonic \& Herrera 2010).

Today some historical 'outbreaks' of the looting phenomenon - Lambayeque and Nasca territory - are under control; however, the problem remains, despite a more careful - but not yet sufficient - control of the origin of the artefacts by museums and auction houses. In addition to the illicit trafficking of works of art as a cause of looting, there are now other factors that are more difficult to manage, such as mining, vandalism, and unplanned urbanization.

The debate between experts, operators, and institutions highlighted the need to intervene in all phases of the 'destructive chain' of knowledge of the human past, including:

- the contrast to clandestine excavations with appropriate on-site surveillance and remote sensingbased monitoring resources

- the hard fist towards intermediaries and collectors, along with the control of land and air traffic, and therefore to that criminal network that allows you to move art objects from their places of origin to collections and museums in the US and Europe

- the increasing awareness about the damage that this activity causes to the heritage and cultural identity of the country of origin of the objects stolen and illegally sold

In reference to the first point, it is important to consider that Earth Observation (EO) technologies represent a fundamental means for the detection and quantification of the damage caused by looters and, therefore, can provide valuable information to contrast looting and support prevention strategies. Over time, satellite EO become the only means for obtaining quantitative information about looting over large and remote areas, as in desert contexts, where direct and aerial surveillance is not practicable, as well as in regions affected by armed conflicts or characterized by flight restrictions. Remote sensing can be used for manifold applications, from the mapping of looted areas to the analysis and understanding of the digging techniques, methods highly useful to contrast the phenomenon and investigate these crimes.

\subsection{RESEARCH MOTIVATION}

In Peru, a multiscale and multisensory approach, including satellite EO, unmanned aerial vehicle (UAV), GPS survey, and georadar was devised by Lasaponara \& Masini (2016) to automatically detect and map looting in the Southern Peru and to provide some 'rescue 
information' about the buried structures. In particular, satellite imagery was processed using Archaeological Looting Feature Extraction Approach (ALFEA), developed by Lasaponara and Masini (2018), to automatically identify and characterize looting patterns in desert environment.

An improvement of the ALFEA (herein named ALFEA-I) is proposed in this paper and applied in two test areas in Central and Northern Peru. This improvement, described in section 4, is conceived to refine the algorithm's ability in the identification and extraction of looting features in a more heterogeneous landscape, characterized not only by the presence of looting patterns, but also by other features as those referable to archaeological micro-relief, emerging remains, natural complex geomorphological features and dirt pathways, which exhibit a similar spectral behavior, but are different in dimensions, morphology, and/or geometric patterns.

On the desert surface, the digging of grave robbers produces patterns characterized by craters or holes of circular and/or quadrangular shape, depending on soil compactness and the time of exposure to wind erosion (Figure 1).

The shadow and the shapes, produced by the microtopographic variations (Figure 1), are very effective proxy indicators exploited in the ALFEA data processing chain for the automatic extraction of looting patterns. The ALFEA processing is based on the sequence of

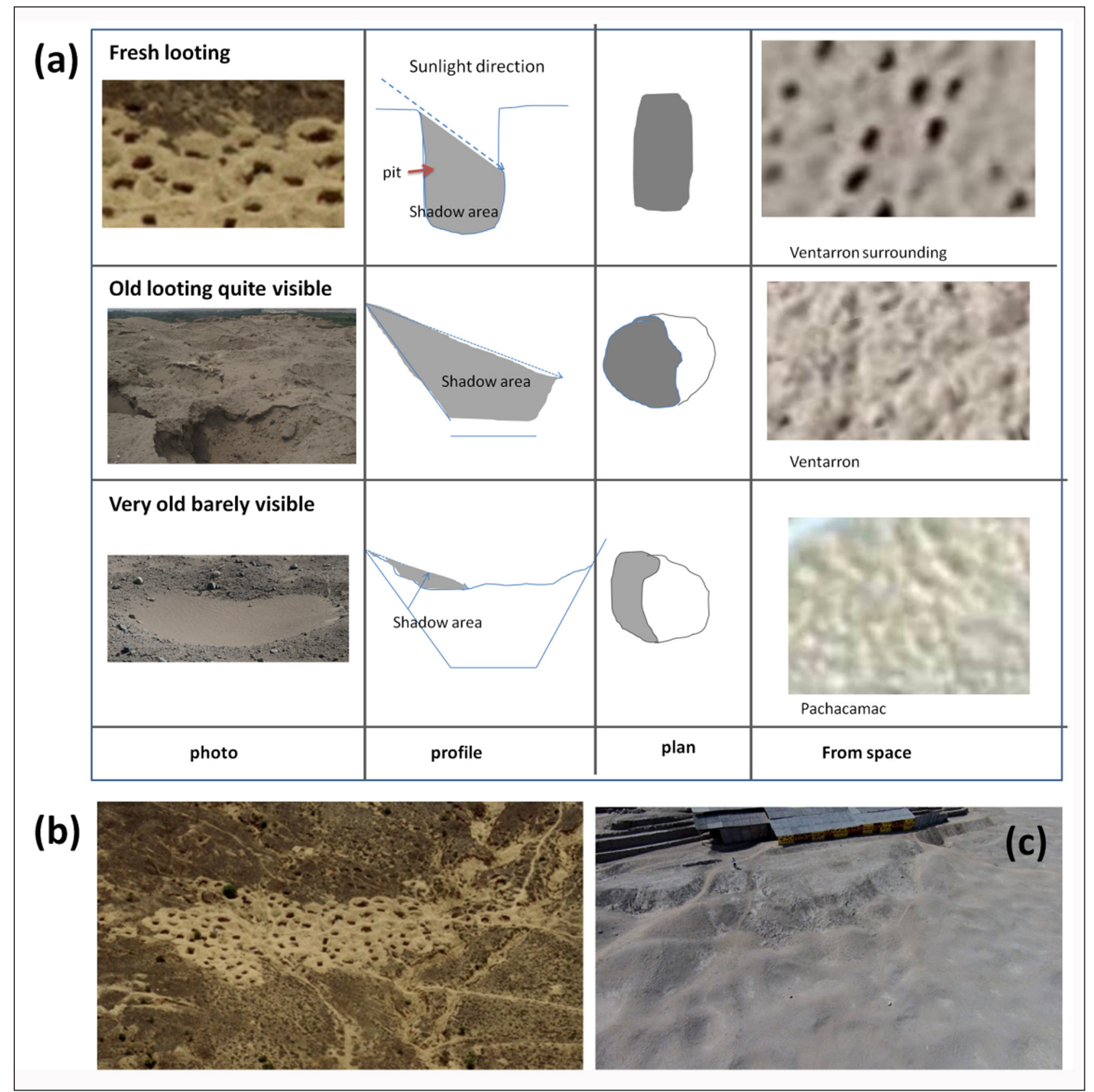

Figure 1 (a) An example of diverse looting characteristics: fresh clearly visible, old quite visible, very old barely visible; depending on the digging period, soil compactness, and the time of exposure to wind erosion. Images in $\mathbf{1}$ (b) and $\mathbf{1}$ (c) are related to fresh (b) and very old (c) looting features, in Ventarron and Pachacamac, respectively; both of them selected as test cases in this paper. 
the satellite based statistical analyses using LISA (Geary), unsupervised classification, and segmentation (Lasaponara \& Masini 2018).

This methodological approach has been herein refined: i) to better discriminate looting features, for both recent and past digging, hence the selection of the two test cases discussed in section 2; and ii) limit misclassifications, caused by the presence of microtopographic variations - not linked to archaeological disturbance - along architectural structures and dirt pathways.

\section{STUDY AREA}

\subsection{PERU AS AN EMBLEMATIC CASE FOR THE ANALYSIS AND THE STUDY OF ARCHAEOLOGICAL LOOTING}

Peru is the country with the largest number of sites of cultural interest in South America, including 100,000 archaeological sites, uncovered by archaeologists and, even more, by grave robbers. This numerical assessment can be considered as only 'the tip of the iceberg' of the potential pre-hispanic archaeological sites in Peru, probably consisting of a number ten times higher.

Looting of the grave robbers - huaqueros in Spanish - is an old problem in Peru, which began in the first centuries of the Spanish colonization (16th-17th century), during the so-called 'search for gold' of the 'Conquistadores' (Doering 1958). An additional factor that spurred looting was the policy of eradicating ancestor worship and extirpating idolatry (Gerdau-Radonic \& Herrere 2010). Due to this, Peru was one of the first countries of America that adopted a specific legislation in 1882 to face looting and protect cultural property, prohibiting the exporting of archaeological objects without the governmental authorization (Batievsky \& Velarde 2006). Unfortunately, this law for the protection of cultural heritage did not provide the expected impact, but only served to recognize the existence of the problem. Moreover, not only it was completely ineffective but, on the contrary, the looting phenomenon grew exponentially during the first decades of the twentieth century throughout the whole Peruvian territory, assuming a large-scale dimension. As an example, particularly relevant was the sacking of archaeological sites of Paracas, described by Julio Tello in the 1920s (Tello 1929).

In the following decades, some amendments to the legislations were undertaken. A new law, approved in 1929, established that the pre-hispanic artefacts belonged to the State. Nevertheless, again as in the past, the adoption of this law did not produce the expected impact in the reduction of the looting phenomenon due to the numerous derogations approved to allow the private ownership rights and to grant the archaeologists in charge of the excavations to acquire property rights for the duplication of objects they found (see Martorell-
Carreño 2006). Subsequently, new laws were adopted in order to define a more extensive concept of cultural heritage and to reinforce the control, but also these did not resolve 'the Peruvian heritage problem' (MartorellCarreño 2006).

For the Peruvian archaeology, the second half of the twentieth century was marred by a devastating increase of looting, as also highlighted in the national and international news (see also Higueras 2008). An emblematic and dramatic event was the looting of 'the treasure of Senor de Sipan' (Alva 2001). The archaeological discovery was marred by the death of some grave robbers, due to the armed intervention of the police.

From the anthropological point of view, the huaqueros in Peru can be categorized into diverse typologies: (i) small-scale looters generally hikers and hunters considered as unpremeditated looters, (ii) artefact collectors, interested in expanding their own collections of ancient artefacts, and (iii) 'professional' looters, i.e. individuals motivated by money, coming from a wellestablished international market. Until the early $20^{\text {th }}$ century, the grave robbers used to work individually; later, they started to work in teams for their own gain or to work for hire (Silverman 1993).

Looting is the major source of artefacts for the antiquities market, and, therefore, the clandestine excavation activity is linked mainly to illicit trade of antiquities especially in Europe and North America (Brodie $\&$ Renfrew 2005). Therefore, to fight this phenomenon, along with the repressive measures and restrictive laws, international conventions imposed the forced return of looted archaeological objects. Nevertheless, this only partially addressed the problem because even if the objects have been returned, the cultural knowledge linked to the settlements they belonged to is lost forever, as also the archaeological context from which they were stolen cannot be recovered anymore. The illegal trafficking of archaeological artefact remains a major problem, even if in the last decades the international cooperation among cultural organizations and museums proved to be quite effective in preventing illicit import and export of artefacts, but often false documentations limit this. Still today, the global dimension of the problem imposes the need to define new strategies to face the plundering of cultural sites in situ, as the use of systematic monitoring to support mitigation strategies. In this context, very high resolution (VHR) satellite data can be useful for the quantification of looted areas, an important key factor to support the contrast and mitigation of looting.

In this paper, we focus on the ALFEA improvement applied and tested in two significant case studies below described $(\$ 2.2, \S 2.3)$ : Ventarron in the Lambayeque region - Northern Peru - and Pachacamac, close to Lima. 


\subsection{VENTARRON CASE STUDY}

The archaeological site of Ventarron is located on the west side of the slopes of the hill Cerro Ventarrón, $1 \mathrm{~km}$ from the Reque river, in the Department of Lambayeque - Northern Peru.

It is characterized by an extraordinary long cultural continuity. A 4,000-year old temple, covering about 2500 square meters, started to be excavated in 2007 by the archaeologist Walter Alva, who unearthed probably the oldest wall painting ever found in America (Alva Meneses 2013).

In the last decade, the archaeological research has been enlarged to the territory surrounding Ventarron, including Arenal and Cafetal, placed on a sandy area at the foot of the western and southern slope of the Cerro Ventarrón, respectively.

A rich archaeological record dated back from the Initial period (1800-900 BC) to the Moche age (100 AD to 800 AD) was found (Alva Meneses 2013). Unfortunately, the area has been devastated by continuous plundering and profanation of tombs, which reduced the potential archaeological resources, thus making very difficult the understanding and reconstruction of the different phases of human frequentation.

Arenal along with an area at South West of Cafetal (see Figure 3 ) has been already used as test case for the validation of a method devised to enhance and extract looting patterns using autocorrelation statistics and unsupervised classification (Lasaponara et al. 2014).

In this paper, the test site is a sector located at East and South East of Cafetal (see Figure 3), characterized by wall remains related to Inca earthen enclosures, known as tambo (Alva Meneses 2013).

This sector has been selected because it is characterized by a heterogeneity of features: i) anthropic, including archaeological micro-reliefs and looting holes, and ii) natural, from bushes to outcropping rocks, in order to effectively test the capability of ALFEA-I in discriminating archaeological looting features.

For the test of ALFEA-I, GeoEye multispectral imagery acquired on 09/09/2010 have been used.

\subsection{PACHACAMAC CASE STUDY}

Pachacamac, the most important oracle of Peru in the prehispanic times, is located on a desert hill at $31 \mathrm{~km}$ South East of Lima (Figure 2). It covers an area of 465 hectares, occupied for the 30 per cent by temples, palaces, and pyramids with ramp, some of them seriously affected by looting over time (Figure 4). The site was a ceremonial center characterized by a long human frequentation that started between the Initial Period and the Early Horizon (1000-800 BC), during the Chavin cultural influence.

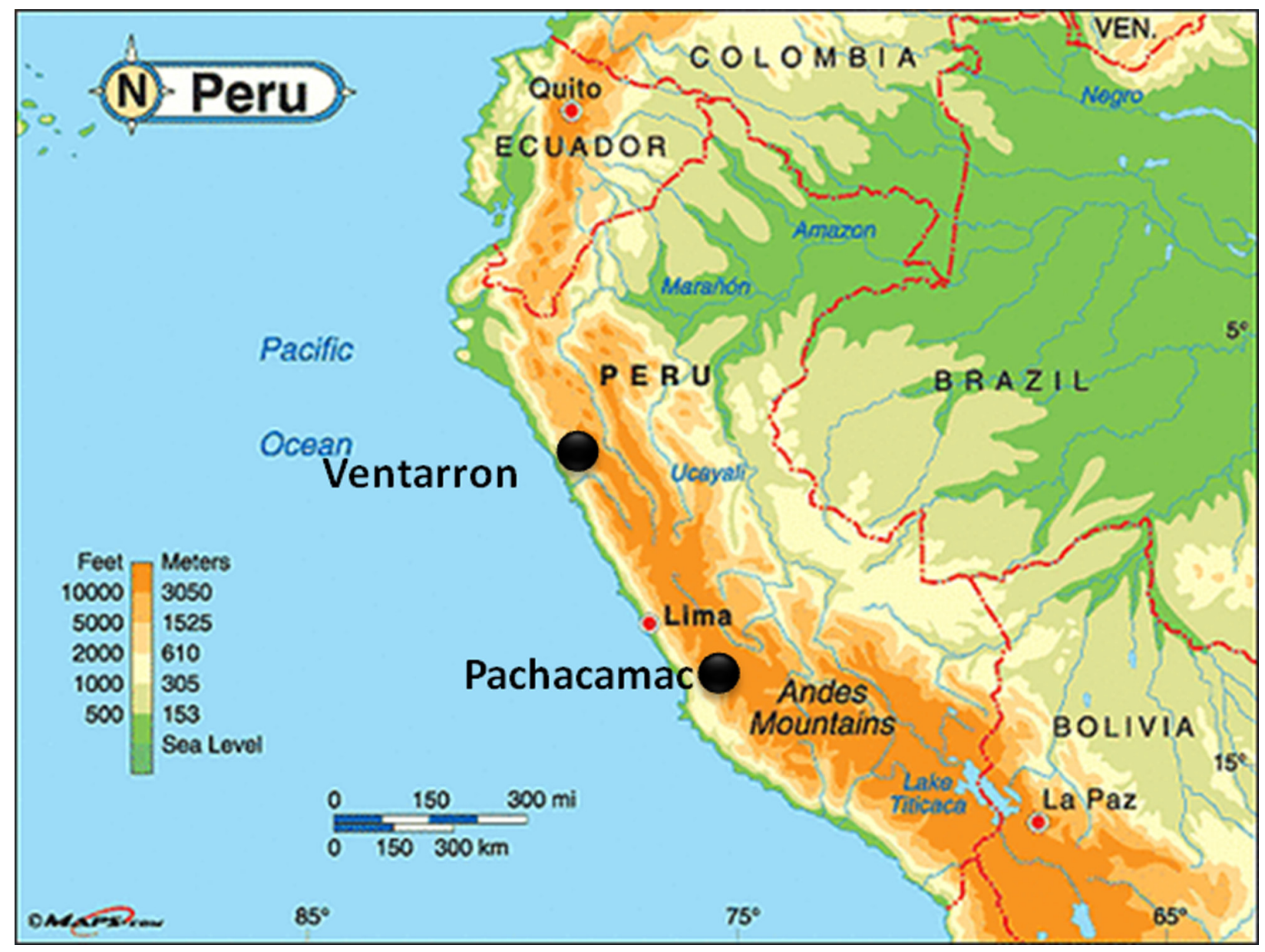

Figure 2 Location of the case studies Ventarron and Pachacamac in Northern and central Peru. 

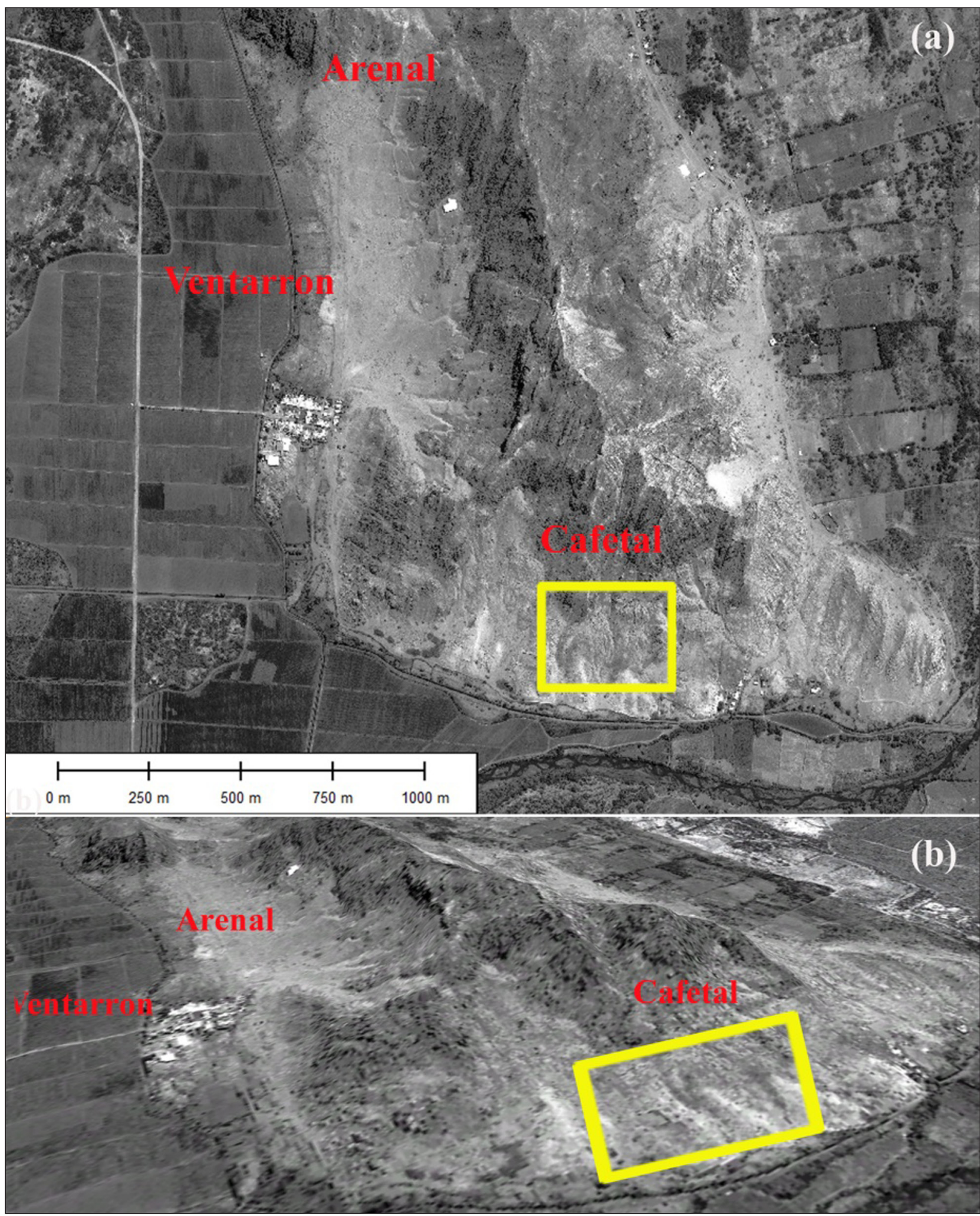

Figure 3 (a) GeoEye satellite panchromatic image of Ventarron acquired on 09/09/2010. The yellow box indicates the investigated area in Cafetal; (b) $3 \mathrm{~d}$ satellite image view. Yellow box indicates the test area.

Pachacamac reached its apogee during the Huari period (550-1100 AD), when the sanctuary became a city settled as an administrative center of great importance throughout the Andes (Shimada 1991). Still today, the Huari influence is clearly visible in objects, ceramic, as well as in the architectural remains and paintings, as in the case of the so-called Templo Pintado (Painted Temple) (see Figure 4).
After the collapse of the Huari, the Ychma (11001470) civilization flourished as evident in its architectural achievements, as the typical Pyramids with ramp (Eeckhout 1995). Later on, during the Inca Empire, Pachacamac was a very important ceremonial and administrative center, (as evident by the impressive buildings and the Taurichumpi urban settlement) for 


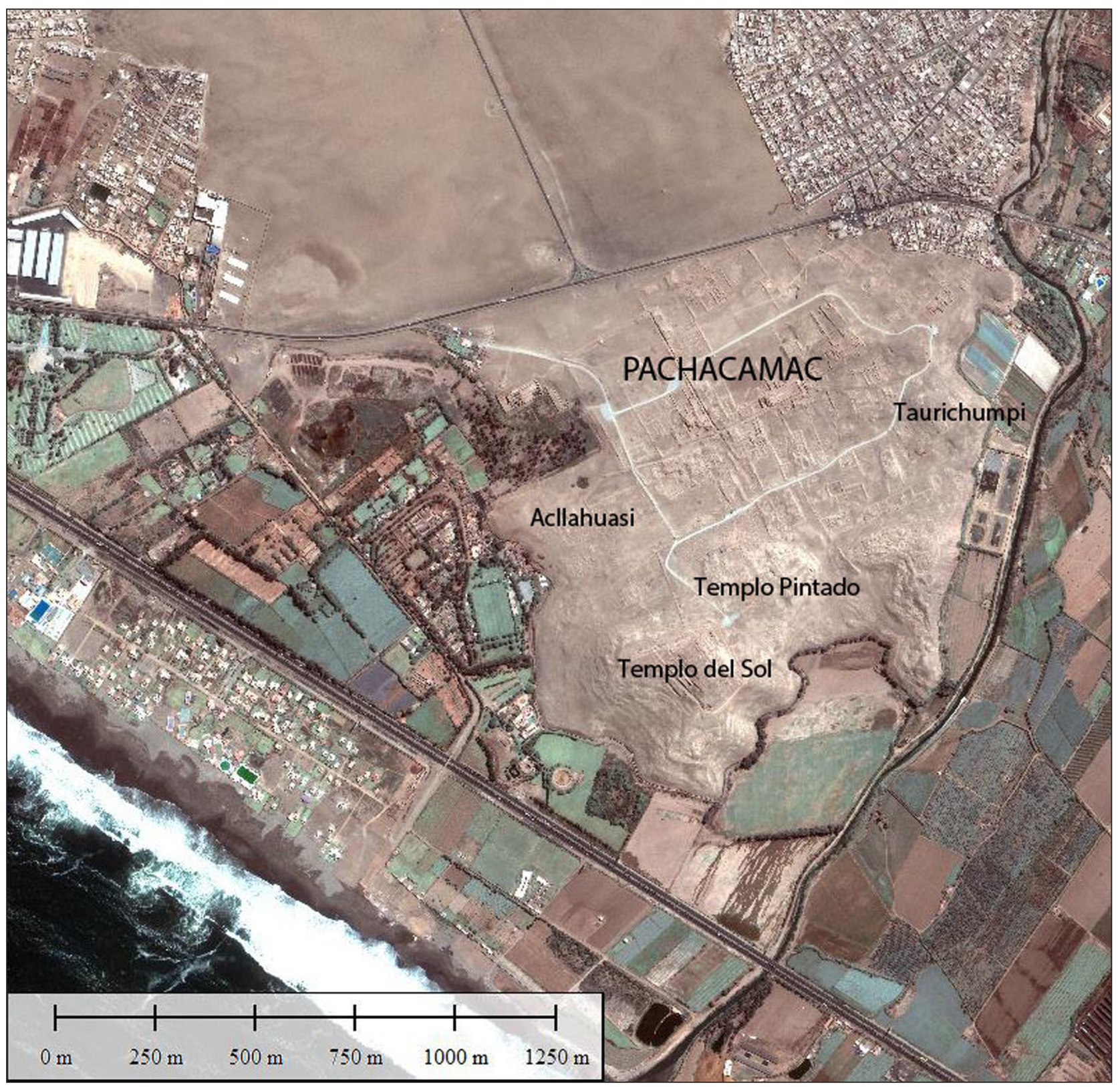

Figure 4 Pleiades true color satellite image of Pachacamac acquired on 13/04/2013. The test site is around Templo Pintado, selected for its importance, which attracted the greedy grave robbers who devastated the areas surrounding the temple.

which the Incas maintained the sacredness of the place, with the magnificent temples they built as the Temple of the Sun, along with the Acllahuasi palaces.

For the purpose of our investigations, the test area was selected close to Templo Pintado which is a stepped pyramid richly embellished with mural painting, including multicolor figures of people, plants, fish, and marine animals (Ravines 1996). Before the arrival of the Spaniards, the Templo Pintado housed the famous wooden idol of Pachacamac, carved with human figures and animals, which was an oracle revered by the Incas. Hernando Pizarro, who linked the artefact to apparent "devil" worship, removed it. Unfortunately, the fury towards the Templo Pintado continued in the following centuries. The importance of the temple attracted the interest of grave robbers who, in several stages, damaged, through devastating digging, the areas surrounding the temple. For this reason this area has been chosen as a case study for our remote sensing based applications, using satellite Pleiades multispectral imagery, acquired on 13/04/2013, along with UAV based surveys.

\section{REMOTE SENSING TOOLS FOR THE IDENTIFICATION, QUANTIFICATION AND CHARACTERIZATION OF LOOTING PHENOMENON}

\subsection{SENSING LOOTING FROM SPACE}

What is the advantage of observing looting from above? What is the contribution to the study of the phenomenon and what indications can be drawn to counter it?

To answer these questions we refer to some past experiences in desert environment in South (Lasaponara 
\& Masini 2016) and North Peru (Lasaponara et al 2014). First, it is important to consider that in arid and desert surfaces the typical looting patterns and their morphological characteristics can facilitate the identification and recognition of areas disturbed by grave robbers.

The shape (generally curvilinear) and dimensions can vary according to the degree of compactness of the ground and the "digging technique" used (by hand or mechanized) and the time of exposure to erosive phenomena, from which can be possible to draw chronological-relative information on the time of the illegal excavations.

Considering the size (diameter) of the looting holes, it is generally possible to estimate the depth of the dig. In particular, it should be considered that for the stability of the hole itself, in sandy desert, deeper the dig larger the diameter and consequently the devastation, along with the greater ‘technical organization' (Lasaponara \& Masini 2016).

Based on the diameter of the top of hole (the major base of the truncated cone), along with the geological and geotechnical characteristics of the soil (including the angle of the trench), it is possible to estimate the depths for the diverse hole diameters, which, in most cases, well fit with the excavation depths of the archaeological findings (see Orefici 2016). In the case of holes characterized by minor diameters and, therefore, minor quotas, often the dig did not achieve the depths of archaeological interest. This was also revealed by the results obtained from some testing geo-radar survey, which revealed the presence of archaeological features below the level of the digging made by the grave robbers (Lasaponara \& Masini 2016; Lasaponara et al 2014). Another element of interest is the analysis of the pattern of the looting holes from which it possible to understand the degree of organization, along with the knowledge of huaqueros about the 'archaeological potentiality' of the site, and deduct a 'relative chronology' of the excavation phases (Silverman 1993).

Moreover, it was possible to identify at least three different looting patterns.

One is characterized by equi-spaced holes, having the same size, and therefore, drawing a regular pattern typical of a good organization and knowledge of the areas, generally supported by an efficient 'trans-regional' network of grave robbers, transporters and collectors.

A second typology is characterized by irregular pattern as result of an organization technique based on a first check using 'a trial digging phase'. In the case of finding, larger craters with diameters up to 7-8 meters were dug. This looting typology are generally perpetrated by local teams for their own gain, working for hire, or also starting from a casual finding.

Finally, the third typology is the 'revisit' of places already looted in the past; this is probably linked to the action of experts and organized grave robbers with a good knowledge of the 'archaeological potentiality' of the sites.

What has been above said highlights the usefulness of remote sensing in facing the archaeological looting, not only as a mere, albeit useful, accounting of the holes dug by grave robbers and calculation of the disturbed areas.

From the morphological-dimensional analysis of the looting patterns, in case of digging in progress, it is possible to obtain information useful to timely intervene, also in remote areas, to stop the ongoing clandestine digging and, possibly, identify grave robbers and the criminal organization.

\subsection{REMOTE SENSING OF ARCHAEOLOGICAL LOOTING: BRIEF OVERVIEW}

The effectiveness of the monitoring of looting using VHR passive and active satellite data (see the overview by Tapete \& Cigna 2019), has been already experienced in Peru (Contreras 2010; Lasaponara, Danese \& Masini 2012, Lasaponara et al. 2014) as well as in areas of ongoing conflicts as Iraq and Syria (Casana 2015; Casana and Panahipour 2014; Stone, 2008; Van Ess et al. 2006; Tapete, Cigna \& Donoghue 2016).

In particular, focusing on Peru, Contreras (2010) used the photointerpretation of aerial and satellite imagery to identify looting damage in the Virù valley. Lasaponara and Masini devised a semiautomatic $(2010,2012)$ and later an automatic (2014) satellite based approach to detect the looted areas in Cahuachi (Nasca) and Ventarron (Lambayeque, Peru). Both of these two sites are considered among the most important archaeological sites in Southern America, and strongly affected by illegal diggings at an "industrial" scale.

Focusing on Middle East including those regions with ongoing conflicts, Van Ess et al. (2006) applied object oriented knowledge-based software for the identification of looted areas near Uruk-Warka (Iraq); Stone (2008) investigated the extension of the damaged areas and the chronology of looting using a QuickBird time series. Casana and Panahipour (2014), in the framework of a NASA-funded project, developed a comprehensive archaeological site database for Syria and surrounding regions. This database included 15,000 sites in Syria and was later updated (Casana 2015) to map the damages, vandalism and looting perpetrated by the Islamic State militants. Cerra et al. (2016) proposed texture features and Gabor filters to detect looting in Syria and in Iraq. Tapete, Cigna and Donoghue (2016) developed a SAR backscattering modelling and texture extraction based approach for imaging looting marks in Apamea (Syria), which has also been investigated by Agapiou (2020) to test the potentials of freely distributed mediumresolution satellite images for detecting large-scale looted areas. El-Hajj (2021) proposed an approach to generate disturbance patches, related to looting 
and destruction areas, using Copernicus Constellation Sentinel-1 and Sentinel-2 classified by Machine Learning.

Using VHR optical satellite data, Lasaponara \& Masini (2018) developed an automatic based approach (the above-mentioned ALFEA method, for which an improvement is proposed and described below in § 4.2) comparing the results in two sites in Syria (Dura Europos) and Peru (Nasca).

Dedicated international studies and projects have contributed to creating networks and platforms for sharing data, good practices and the development of new methodological approaches to looting and the illicit trafficking of works of art.

Among which we cite H2020 Netcher project that aims at creating a structured network of actors engaged in fighting archaeological property pillage (Netcher 2020) and the study by Brodie \& Yates (2019) on Illicit trade in cultural goods in Europe, with particular reference to the applicability of technologies in the combat against the trade.

\section{METHODOLOGY \\ 4.1 ALFEA METHOD}

ALFEA method is based on the following steps: (i) identification of satellite-based parameters to process; (ii) extraction of spatial patterns linked to illegal excavation using geostatistical analysis; (iii) automatic classification and segmentation; (iv) mapping and validation.

The core of the method consists in the unsupervised classification and in the segmentation steps. The unsupervised classification is applied to the LISA of VHR satellite panchromatic as well as to pansharpened multispectral imagery.

LISA is applied to enhance the texture in order to capture the presence of spatial patterns and/or structure, along with texture and form of spatial dependence from the data (Anselin 1995).

Texture informs us about the spatial arrangement of the intensities (pixel values) in an image, and this can be used to improve segmentation or classification process. Actually, there are several statistical approaches devised to analyze an image texture using a set of metrics (as, for example, but not only, spatial frequency and an average grey level) designed to quantify the arrangement of intensities. For example, the presence of edge and the number of edge pixels in a specified region enables us to determine and characterize the complexity of texture, and the direction of the edges can be useful to identify patterns. The autocorrelation function can be used to detect repetitive patterns of textures, the co-occurrence matrix captures spatial relations of similar grey that can be used to represent, compare, and classify textures. LISA approach offers specific metric "denoted” as Getis-Ord Gi, Moran's I, and Geary's C.
- Getis-Ord Gi index identifies areas characterized by significantly higher or lower values compared to those of neighboring pixels.

- Moran's I detects both positive and negative spatial correlations ranging from approximately +1 to -1 which represents complete positive or negative spatial autocorrelation, respectively.

- Geary's C index identifies edges and areas characterized by discontinuities.

All of LISA metrics provided a good enhancement of the looting features in desert environment (Lasaponara, Danese \& Masini 2012; Lasaponara et al. 2014), thus improving the unsupervised classification. Adding the segmentation step (in ALFEA), the best enhancement was obtained from Geary's C (Lasaponara \& Masini 2018).

For an effective application of Geary's C analysis, it is crucial to select the lag and neighborhood rules appropriately. The size and the shape of the targets under investigation condition the selection of these parameters. Both lag1 and lag2 were applied. For the looting target, lag1 provided the best results. Finally, as regards the neighborhood rules, given the morphological characteristics of the feature/target to be enhanced, the Queen's case (selecting all eight neighborhood pixels) has been assumed.

However, it is important to consider that image texture is not a perfect measure for segmentation but must be complemented with other measures. For this reason, in ALFEA the segmentation is performed after the classification. Moreover, thischoiceis givenbythespecificity of archaeological looting features, which generally are partially or totally unknown and characterized by a very small spectral separability from the background. In order to overcome these complexities, the first step is based on the unsupervised classification, which provides a first 'rough' categorization of pixels, and the second step is the segmentation, which enables us to extract the geometric shape, and, in turn, to only categorize as looting those pixels geometrically clustered. This approach has two advantages: i) it does not require knowing and assigning a priori pre-established statistical distribution of classes as in the case of supervised classifications; ii) it allows us the identification and extraction of subtle signals/ patterns exhibiting geometric shape, even if veiled by the presence of scattered material.

To automatically detect the areas affected by looting, the results from the Geary's C were classified using the ISODATA unsupervised classification algorithm. This classification requires limited human intervention in setting up the algorithmic parameters. Moreover, also the choice to perform the classification (unsupervised) first and then the segmentation, was made herein to reduce the parameters to be selected in order to extract geometric features that are obtained by setting only: i) the minimum number of pixels to be considered in 
a region for building a segment; and ii) the number of neighboring pixels which determines the separability/ connectivity of the segments.

\subsection{ALFEA IMPROVEMENTS}

The ALFEA has been improved to be successfully applied also to heterogeneous desert landscapes, in order to discriminate looting patterns from archaeological and geomorphological features, which exhibit a similar spectral behavior but dimensions, morphology, and geometric patterns different from those linked to looting.

For this purpose, the segmentation phase has been split according to different thresholds of the parameters - the population minimum ( $\mathrm{pm}$ ), and the number of neighbors (nn). To maintain the general applicability, we set three different sizes, herein denoted as small, medium, and large dimensions, where for:

- small features (sf), we mainly refer to dimensions ranging from 4 to 6 , related to most of looting pits (with diameter from 4 to $6 \mathrm{~m}$ )
- medium features ( $\mathbf{m f}$ ), we refer to dimensions ranging from 6 to 10, related rarer big looting features (that are real craters with diameters greater than $6 \mathrm{~m}$ ), geomorphological features, microrelief, and earthen low walls of medium length

- large features (lf), we refer to dimensions greater than $10 \mathrm{~m}$, related to roads, higher walls (from 1 meter up) with medium and large length, and geomorphological features

The above listed multiscale feature characterization, suggested to assume three segmentation sets S1, S2, and $\mathrm{S3}$, assuming the threshold values of the population minimum (pmi) and the number of neighbors (nni).

S1 includes small to large features, S2 medium to large features, and S3 large features.

The final output (the map of small features) is obtained using the intersection between $\mathrm{S} 1, \mathrm{~S} 2$, and S3, which leave out S2 and S3 from S1 class (see Figure 5, blues boxes).

In the case of the presence of looting holes with diameters larger than $6 \mathrm{~m}$ (belonging to the medium

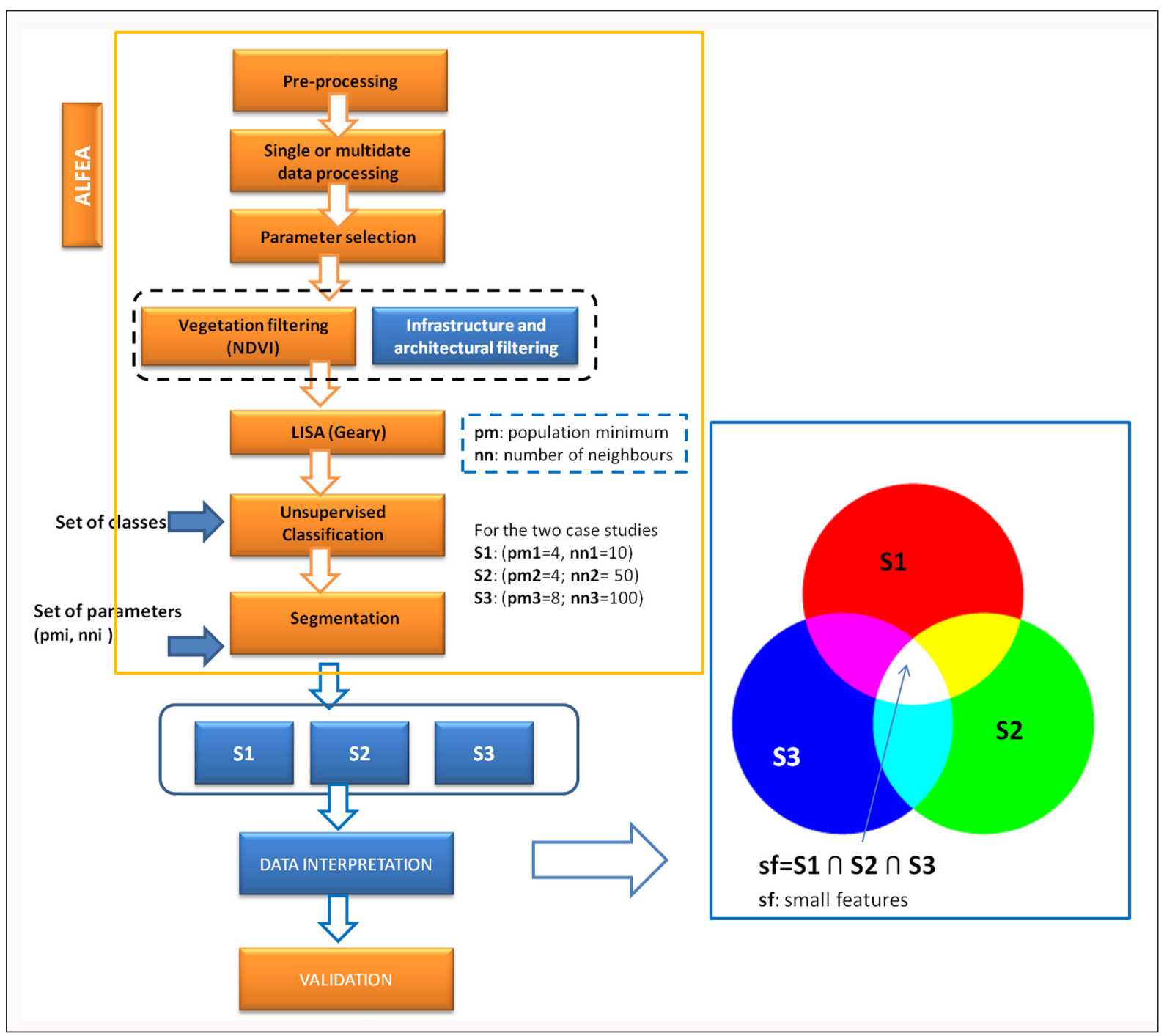

Figure 5 Flow chart of ALFEA-I: orange boxes indicate the ALFEA data processing steps; blue boxes and lines denote the ALFEA improvement. 


\begin{tabular}{|c|c|c|c|c|c|c|}
\hline ACQUISITION TYPE & $\begin{array}{l}\text { ACQUISITION } \\
\text { DATE }\end{array}$ & TIME & N. IMAGES & CAMERA & $\begin{array}{l}\text { DEM } \\
\text { GSD (CM) }\end{array}$ & $\begin{array}{l}\text { ORTHOPHOTO } \\
\text { GSD (CM) }\end{array}$ \\
\hline $\begin{array}{l}\text { Unmanned aerial } \\
\text { acquisition by } \\
\text { Dji Phantom Vision } 2\end{array}$ & 12.12 .2014 & $15: 40$ & 91 & $\begin{array}{l}\text { Camera with the following } \\
\text { characteristics resolution } 14 \\
\text { megapixels, FOV } 120^{\circ} / 110^{\circ} / 85^{\circ} \text {, } \\
\text { Sensor size } 1 / 2.3^{\prime \prime}\end{array}$ & 5 & 2.5 \\
\hline
\end{tabular}

Table 1 Data of unmanned aerial acquisition.

features) in the context of incoherent sandy desert (see the consideration on the stability issues in § 3.1), we suggest to include as final output both small and medium class, highlighted in RGB composition as red and yellow features (see Figure 5).

To facilitate the interpretation S1, S2, and S3 are showed in RGB composition (as showed in Figure $7 \mathrm{~g}$, and 12).

\subsection{UAV BASED VALIDATION}

The validation has been performed based on in situ analyses, along with close range acquisitions performed by drone only in the case of Pachacamac, nearby Templo Pintado. The aim was to identify subtle hole edges of past looting difficult to recognize on site. The images were acquired using a drone Dji Phantom Vision 2, mounting a 14 megapixels RGB camera and processed using Structure from Motion based tools to obtain the orthophoto and DTM of the scene (see Table 1).

To appreciate the microtopography with centimetric details for the detection and characterization of disturbance features, the DTM was enhanced using a number of visualization techniques, including hill shading, Simple Local Relief Model (SLRM) and Sky View Factor (SVF).

SLRM (Hesse 2010) is based on the smoothing of DEM made applying low pass filter, its subsequent subtraction to the initial DEM, the calculation of the zero meter contours from the difference model to obtain break lines, as well as the intersection of the break lines with the DTM.

SVF (Zakšek et al. 2011) quantifies 'the portion of the sky visible from a certain point' within a certain radius. SVF denotes a large portion of the sky visible and the size of the observed area (defined by the chosen radius) impacts on the result. Small radius is required (e.g., 10$15 \mathrm{~m}$ ) to highlight subtle and small-scale micro-relief as expected in the looted area. In particular, SVF delineates mainly concave features and maintain the slope well visible, also preserving the perception of the general topography.

\section{RESULTS}

The section shows the results obtained from the application of ALFEA-I to VHR satellite imagery related to Ventarron and Pachacamac case studies.
The data used for the Ventarron case study are GeoEye multispectral imagery acquired on 09/09/2010.

The validation was made using historical photographs, including panoramic photos captured on the top of Cerro Ventarron, made during the CNR scientific mission conducted in December 2010.

The data used for the Pachacamac case study are Pleiades multispectral imagery acquired on 13/04/2013.

The validation was made by in situ analyses (conducted in November 2013 and December 2014) along with UAV based survey (performed in December 2014). For Pachacamac the availability of UAV survey was essential for the validation due to the difficulty to recognize all the holes on site, being that most of them are old and their edges have been smoothed by wind erosion over time.

The validation has been performed using the following parameters:

- NH: number of holes identified from in situ and close range RS observation

- TD: number of targets (looting pits) detected

- TnD: number of targets not detected

- FA: number of false alarms

From the above listed parameters the following parameter have computed

- \%TD: target detection rate given by $\% \mathrm{TD}=\mathrm{TD} / \mathrm{NH}^{*} 100$

- \%TnD: target non detection rate, given by \%TnD $=\mathrm{TnD} / \mathrm{NH}^{*} 100$

- $\mathrm{N}_{\mathrm{FA}}$ : normalized false alarm index given by $\mathrm{N}_{\mathrm{FA}}=\mathrm{FA} /$ $(\mathrm{FA}+\mathrm{TD}) * 100$

Figure $6 a$ shows the $3 d$ satellite view of the area investigated in Cafetal obtained using a DTM derived from a topographical survey provided by the archaeological mission directed by Ignacio Alva. The $3 d$ images clearly highlights the devastating effects of the plundering activity of huaqueros. The huaqueros in this area, as well as throughout the Ventarron territory, are attracted by the possibility of finding ceramics and gold artefacts, dated to Moche and Chimu periods (Alva Meneses 2013), which generally are in tombs and ritual offerings (Figure $6 b, 6 c$ ). The digging activity also affects the architectural structures as well as low wall remains, foundations and micro-reliefs. Moreover, the holes 
accelerate the damage produced by erosive phenomena, due to rainy and windy events, and therefore contribute to further damage the structures. Starting from the panchromatic image, Figure 7 shows the intermediate and final results of ALFEA-I related to the area investigated in Cafetal.

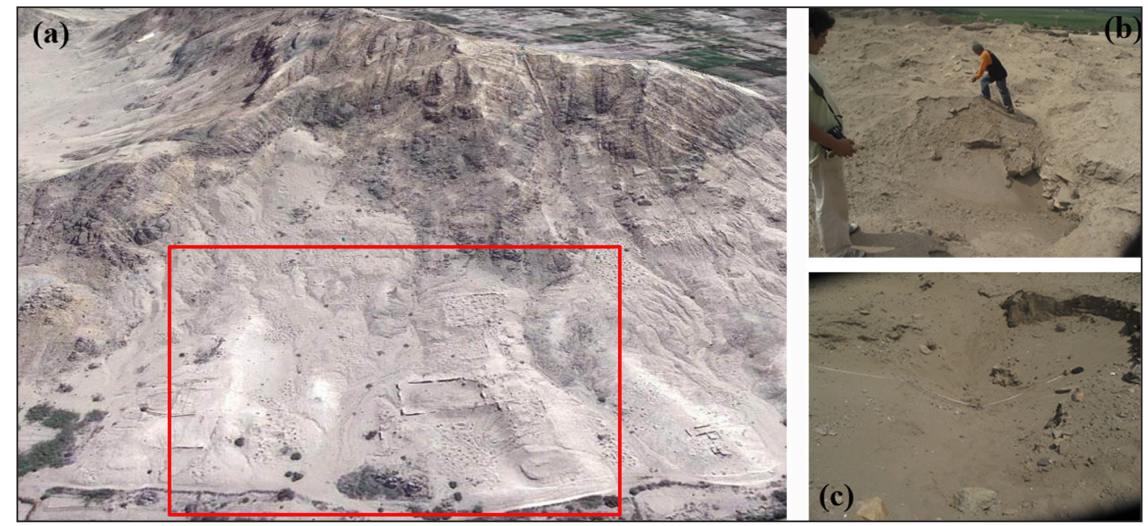

Figure 6 (a) 3d satellite view showing the Ventarron test area (southern and east sectors of Cafetal); (b-c) details of typical looting holes, generally characterized by diameters of around 6-8 m (Photo by Nicola Masini during the CNR geophysical mission conducted in December 2010).
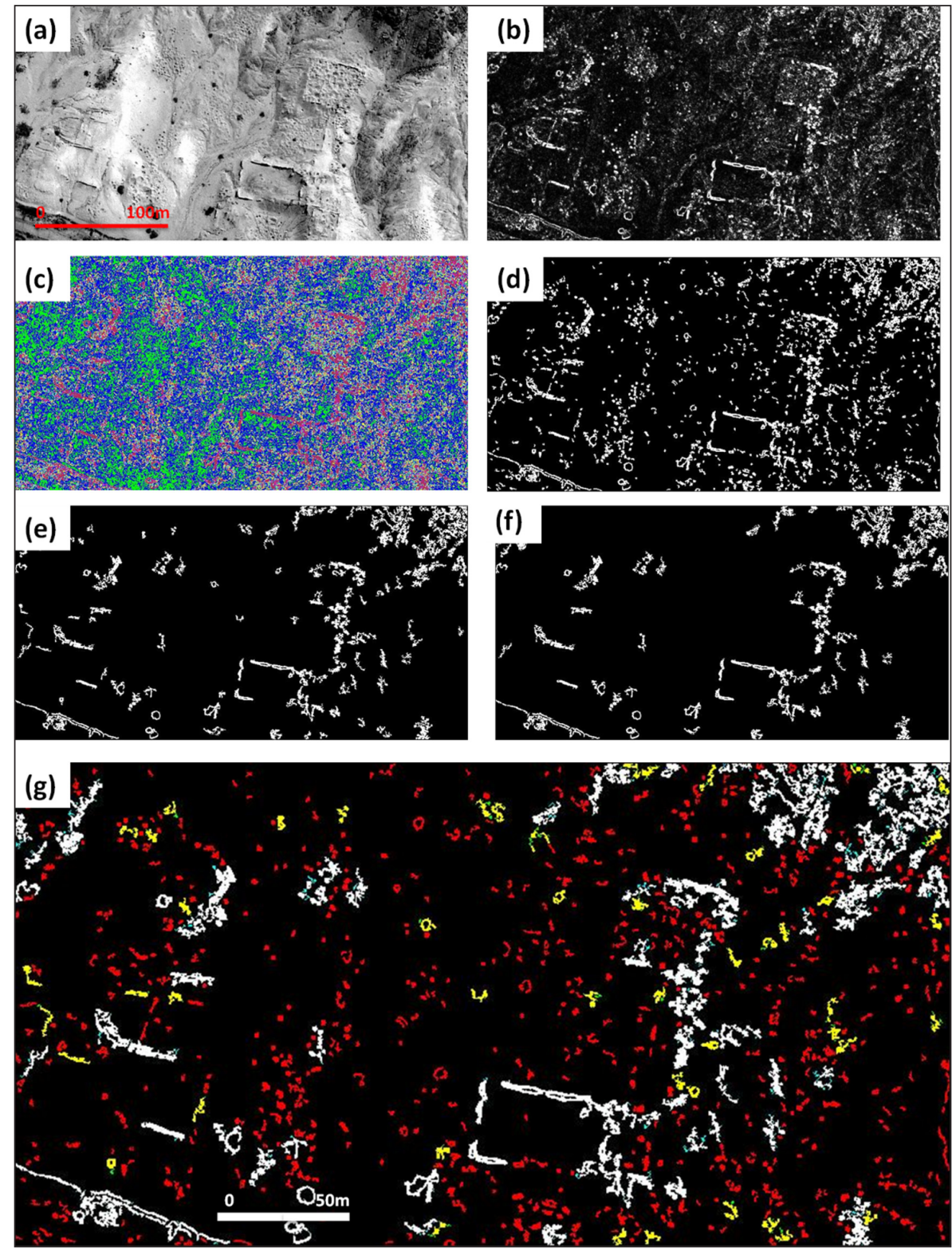

Figure 7 Intermediate and final results of ALFEA-I related to the area investigated in Cafetal (Ventarron). 
Figure 8 shows a zoom of the intermediate and final results of ALFEA-I, evidencing red colored small features related to looting and white colored large segments related to archaeological remains (see Figure 8 , on the bottom).

The three final results are showed in Figure $7 d, 7 e$, and $7 f$. For a clear visualization of the final product, including multidimensional extracted features (as result of multi threshold parameters of segmentation), RGB composition of S1, S2, and S3 has been showed in Figure $7 \mathrm{~g}$.

The red color indicates the small features, most of them referable to looting pits, as confirmed by the results of evaluation of the ALFEA-I rate of success (showed in Table 2), performed by in situ analysis.
In particular, the results (showed in Table 2) are very successful: the target detection rate is equal to 94,6 per cent, the target non detection rate is 9,8 per cent, and the normalized false alarm index is equal to 11,7 per cent.

As regards to the false alarms, some of them are referable to small length microrelief or low earthen adobe walls as showed in Figure 9.

Figure 10 shows the area of Pachacamac most affected by past looting, close to Templo Pintado that, for its importance was particularly damaged by huaqueros in the first half of the 20th century. The analysis of the looting pattern by means of in situ and UAV based observation puts in evidence a large variety of holes in dimension and shape, which suggests that the

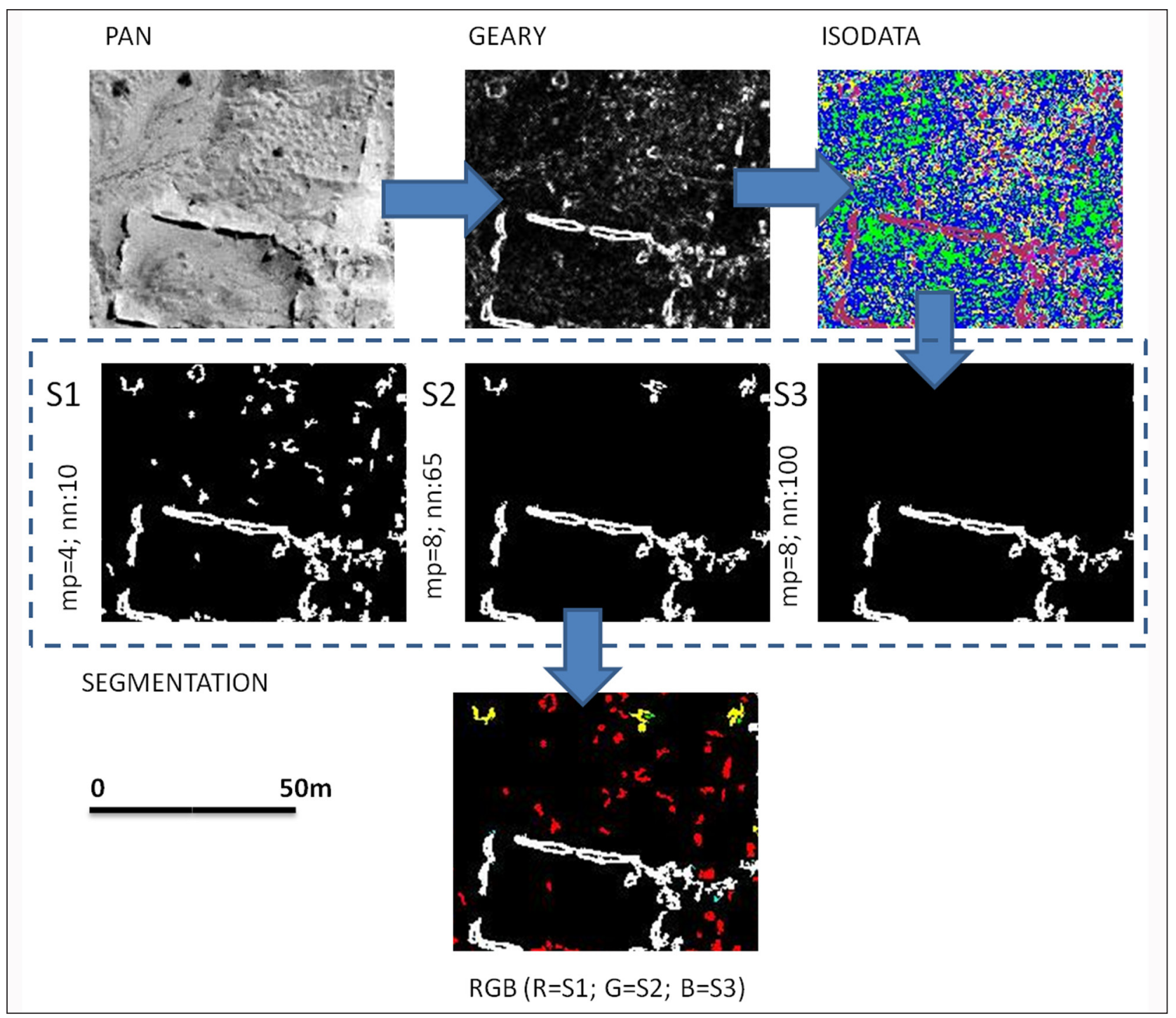

Figure 8 Detail of intermediate and final results depicting small and large features extracted by ALFEA-I.

\begin{tabular}{lllllll}
\hline NH & TD & $\%$ TD & TND & \%TND & FA & N $_{\text {FA }}=$ FA/(FA+TD) \\
\hline 112 & 106 & $94,6 \%$ & 11 & $9,8 \%$ & 14 & $11,7 \%$ \\
\hline
\end{tabular}

Table 2 Rate of success of ALFEA-I. Legend. NH: number of holes identified from visual interpretation; TD: target (holes/pits) detected; TnD: target not detected; $F A$ : false alarms, $N_{F A}$ : normalized false alarm index $\left(N_{F A}=F A /(F A+T D)\right)$. 


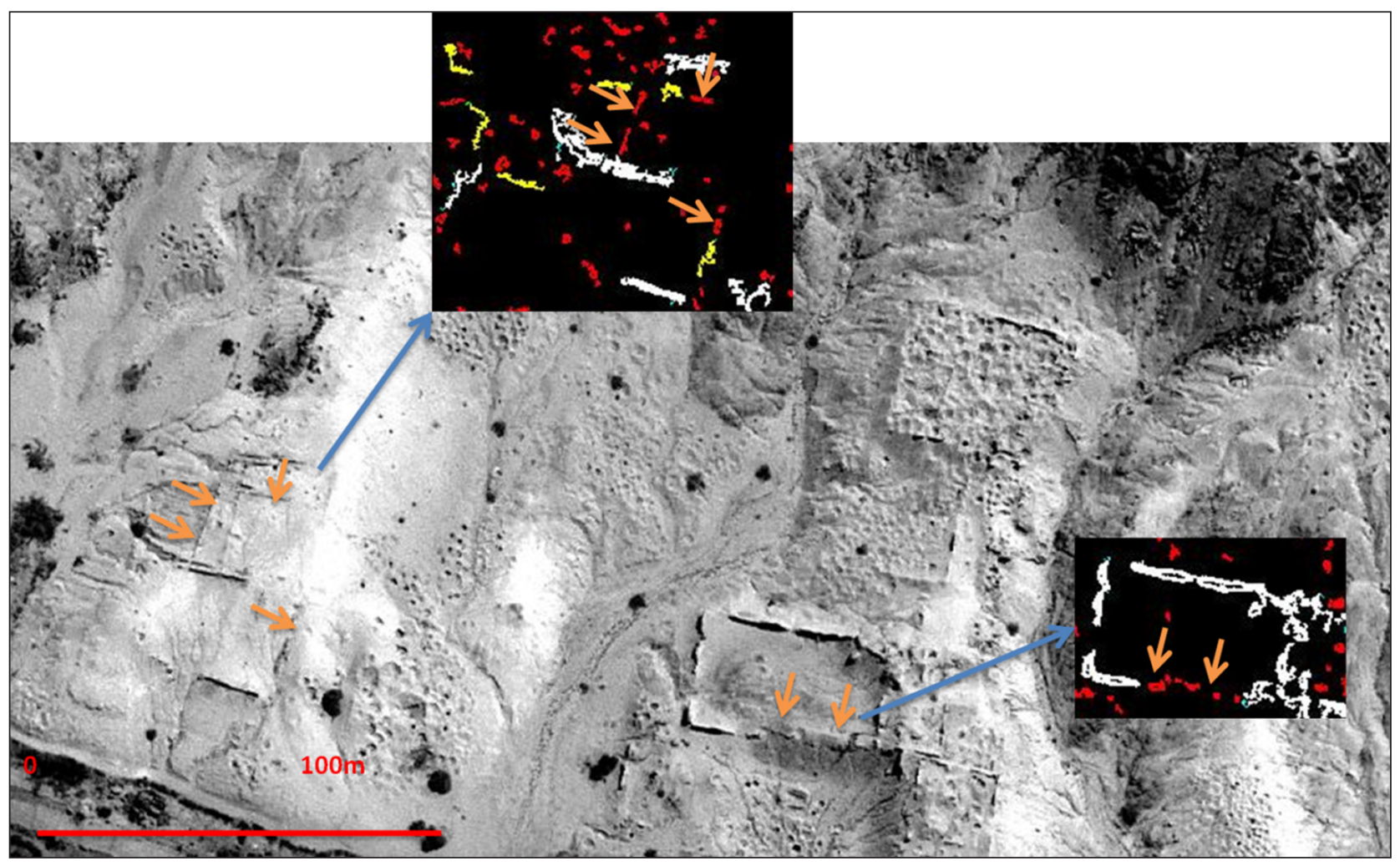

Figure 9 False alarm denoted with orange arrows. They are linked to the presence of small length microrelief and low earthen adobe walls.

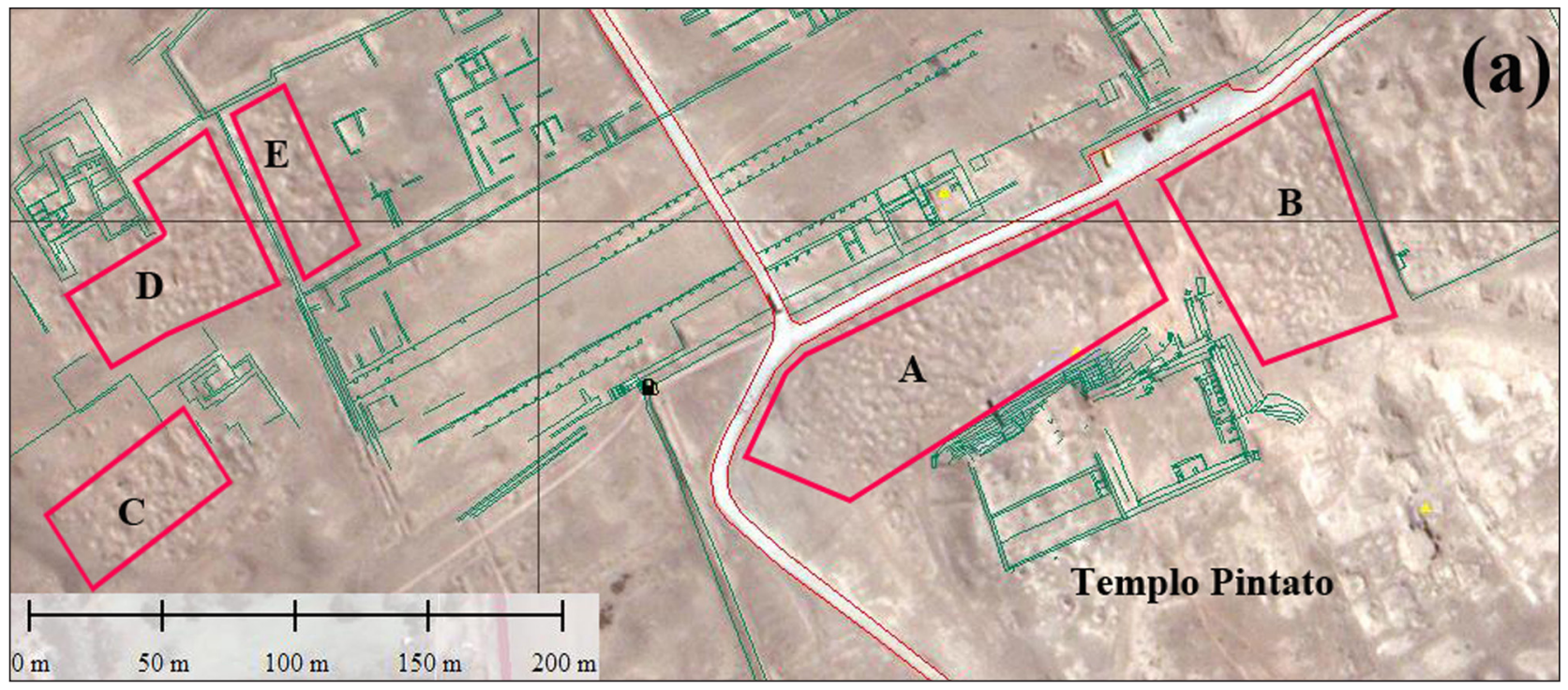

Figure 10 Pleiades satellite based map (acquired on 13/04/2013) with the overlay of the architectural plan (highlighted by green lines) provided by the Museum of Pachacamac (courtesy by Denise Pozzi-Escot). Red polygons indicate the areas most affected by looting. Sector A has been used for the UAV based validation (see also Table 3, Figure 13).

devastation has been probably perpetrated by different groups in different times. This is typical of those sites where the plundering was intensely conducted with very serious damage (see the considerations in §3.1), also strongly fed by the fact that Pachacamac was one of the most important pre-hispanic oracles and Templo Pintado was the core of the ceremonial center.

The wind erosive action makes the recognition of the looting holes in situ and from satellite very difficult.
This highlights the need to perform texture analyses to enhance the subtle features previous the classification, as performed in the data processing chain of ALFEA-I.

Figure 11 shows the intermediate and final results applying the ALFEA-I data processing chain, which is particularly effective in S1, S2, and S3.

Figure 12 shows the final result depicting the three classes of features including small (highlighted in red), medium, and large features (highlighted in red, yellow, 


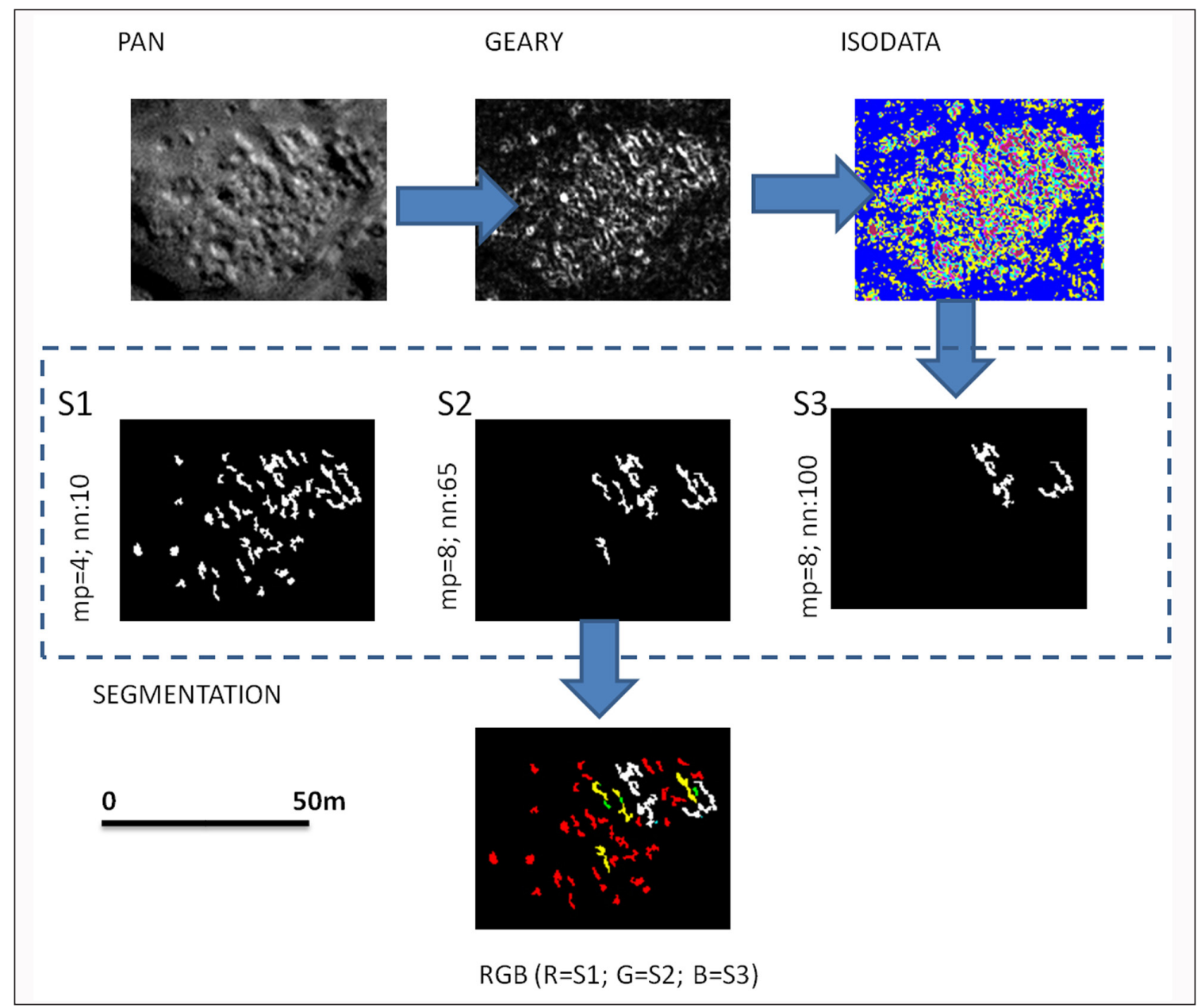

Figure 11 Intermediate and final results depicting small, medium, and large features extracted by ALFEA-I.

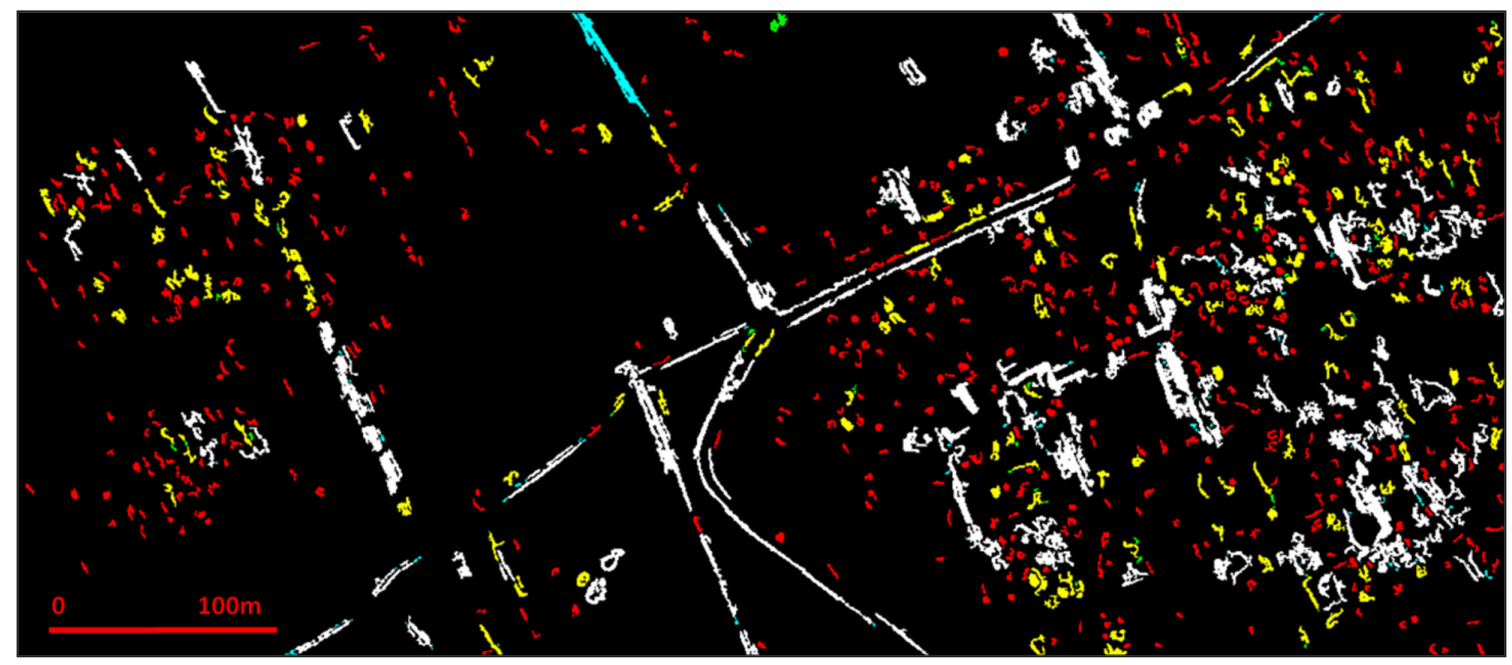

Figure 12 Pachacamac. RGB final result of ALFEA-I method on the entire area.

and white, respectively). Most of the looting targets are included in the small features. However, a significant number of looting holes have been captured by the medium class.

The validation performed in situ and by UAV (Figure 13), with the support of DEM enhanced using SLRM and SVF (Figure 13c) put in evidence a rate of success (\%TD in Table 3) of 71,4 per cent considering the sf class. Including also mf class - see second row denoted with $\left(^{*}\right)$ in Table 3 the \%TD of detected looting features reaches 83,19 per cent. Finally, the normalized false alarm index for both the cases is around the 15 per cent. The achieved results are satisfactory also considering the fact that erosion process overtime smooths strongly the edges of the holes, as showed in the sections $x-x 1$ and $y-y$ ' in Figure 13. The latter puts in evidence the added value of UAV 


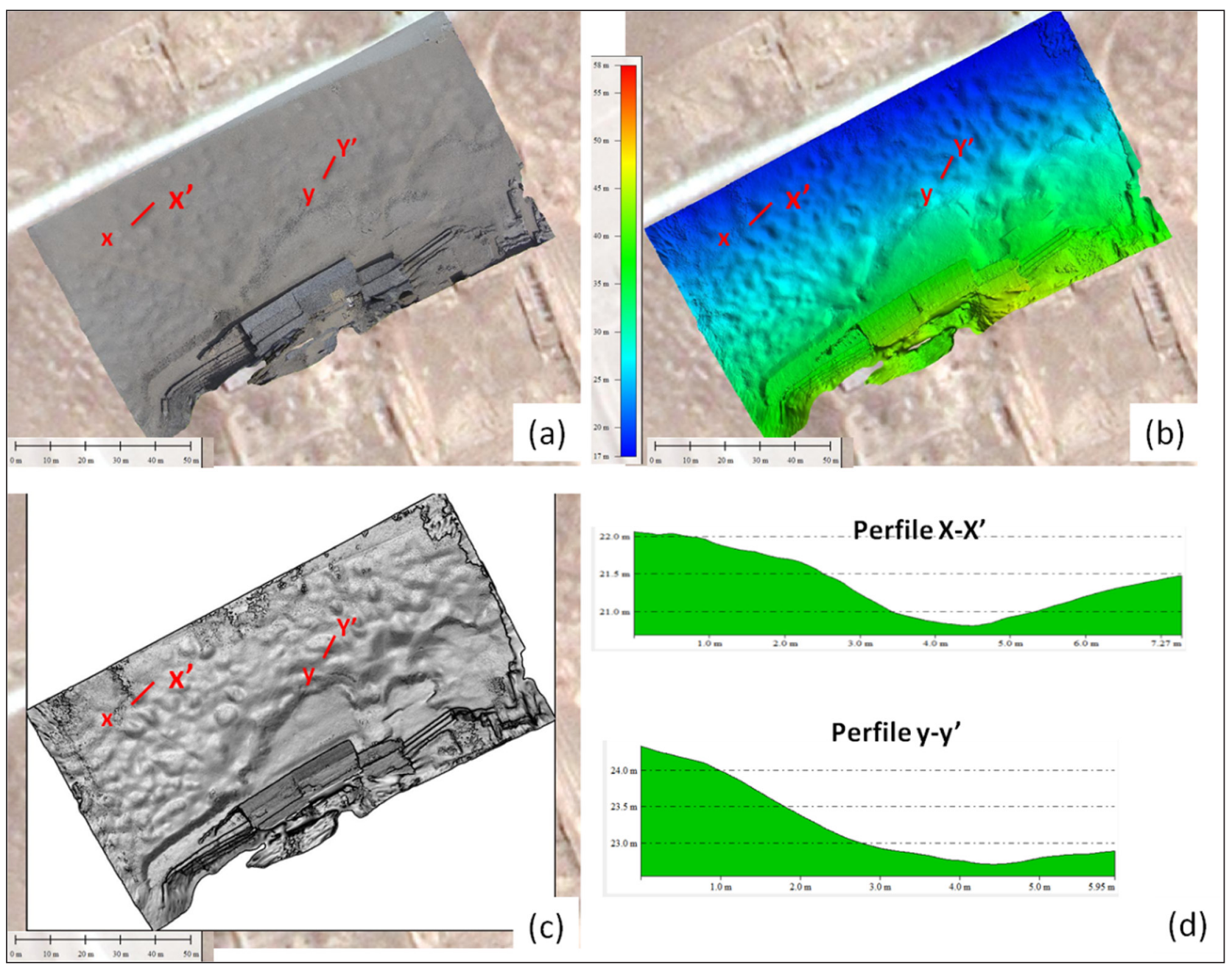

Figure 13 Pachacamac, sector A. UAV based characterization of two looting holes, of which one (section $x$ - $x$ ') is more visible than the other (section $y$-y') because less affected by wind erosion. In detail: (a) orthophoto; (b) DTM; (c) SkyView Factor; (d) sections $x$ - $x^{\prime}$ and $y-y^{\prime}$ measured among the edges of the holes.

\begin{tabular}{lllllll}
\hline $\mathrm{NH}$ & $\mathrm{TD}$ & $\% \mathrm{TD}$ & $\mathrm{TND}$ & $\% \mathrm{TND}$ & $\mathrm{FA}$ & $\mathrm{N}_{\mathrm{FA}}=\mathrm{FA} /(\mathrm{FA}+\mathrm{TD})$ \\
\hline 56 & 40 & $71,4 \%$ & 16 & $28,6 \%$ & 7 & $14,9 \%$ \\
\hline $56\left({ }^{*}\right)$ & 47 & $83,9 \%$ & 9 & $16,1 \%$ & 9 & $16,1 \%$ \\
\hline
\end{tabular}

Table III Rate of success of ALFEA-I in Pachacamac (sector A). The data related to second row * are related to both $\mathbf{s f}$ and $\mathbf{m f}$ classes.

close range acquisitions, using hill shading and SkyView Factor, in improving the visibility of the curvilinear hole edges linked to past looting.

\section{CONCLUSIONS}

In recent decades, the availability of data from EO technologies for archaeology and the study, documentation, and preservation of the human past is stepping into a golden age. Today, the main critical, challenging aspect is a lack of effective methods to automatically extract relevant and useful information, linked, in the case of looting detection, with the recognition and monitoring of buried/lost archaeological sites. The large amounts of EO data will unimaginable increase in the next future - more than we can handle - and this further imposes the setting up of automatic recognition tools.

These aspects are considered a priority at international level with important scientific, cultural, social, and economic repercussions. Among the preservation issue, the quantification of looting is one of the most pressing to address. In this context, it is important to highlight that looting marks generally do not exhibit clear and clean patterns or edges even in high-resolution data sets acquired from both active and passive sensors (see Tapete, Cigna \& Donoghue 2016 and Lasaponara \& Masini 2018, respectively). This is because looting marks are characterized by small spatial/spectral signals, and, in turn, by low geophysical signal compared to their surroundings. 
Moreover, the looting marks are generally not isolated, but mixed with other features and may also appear quite different within the same image due to their diverse physical characteristics (difference in soil type, moisture, land use, and cover). In addition, it must be considered that there are numerous factors, such as noise, and contaminations, that tend to further distort the spectral/ spatial/temporal feature of the looting "signal".

To achieve the automatic recognition of the target of interest, their enhancement is a mandatory preliminary step, as suggested by the same authors of this paper (Lasaponara et al. 2014) who developed an approach based on spatial autocorrelation statistics and unsupervised classification. The feature extraction capability of the approach has been enhanced by ALFEA (Lasaponara \& Masini 2018) based on the sequential integration of spatial autocorrelation statistics, unsupervised classification, and segmentation, to improve the discrimination and automatic extraction of looting features (see $\S 4.2$ ).

Finally, a refinement of ALFEA (ALFEA-I), adding a processing step based on multi threshold parameters of segmentation, is herein proposed for improving the performance in terms of extraction capability of looting features in case of heterogeneous areas in desert environment, as showed and discussed for two significant case studies in Peru, Pachacamac and Ventarron.

The first case is characterized by past clandestine digging, whose looting are difficult to recognize in situ and from satellite images, whereas the second is related to more recent archaeological disturbance of grave robbers, more easy to identify from remote sensing data.

In particular, the ALFEA-I improved the performance in terms of extraction capability of looting features in case of heterogeneous areas. Finally, the integration of satellite based data processing with UAV based close range acquisitions proved to be effective in enhancing the visibility of old looting features, crucial for the validation of ALFEA-I.

Until now, the ALFEA has been used in contexts in which the authors already knew of the presence of clandestine excavation activities. In the future it is desirable to identify looted areas not only on the basis of direct information but on EO-based multitemporal analyses with free medium resolution satellite data, to be followed by the acquisition of high resolution data by applying the ALFEA.

The availability of open data and cloud resources as for example Google Earth Engine (GGE), offers the possibility to set tools that once validated can be immediately applied to the whole globe (Lasaponara et al. 2021). The next step to improve ALFEA-I can be the joint use of medium resolution in GGE to identify the areas of potential anomalies to be further zoomed with the VHR data that will provide detailed information as presented in this paper. Moreover, the ALFEA-I can be suitably and effectively applied to VHR active data as SAR (COSMO, TERRA, etc. today available at $0.3 \mathrm{~cm}$ ) or UAV Lidar.

\section{ACKNOWLEDGEMENTS}

The investigations have been funded by Joint Laboratory of Pre-hispanic Archaeological Science (LaPAS) funded by CNR and the Italian Ministry of Foreign Affairs.

We thank the archaeologists Denise Pozzi Scott and Ignacio Alva for their support in our investigations in Pachacamac and Ventarron, respectively; Antonio Pecci for UAV based acquisition and processing orthophoto and DTM of Pachacamac, Maria Sileo for her contribution to field surveys.

\section{COMPETING INTERESTS}

The authors have no competing interests to declare.

\section{AUTHOR AFFILIATIONS}

Nicola Masini (D) orcid.org/0000-0002-8804-5718

Institute of Heritage Science, CNR-ISPC, Italy;

C. da S. Loya, 85050 Tito Scalo, Potenza, Italy

Rosa Lasaponara (1D) orcid.org/0000-0002-1287-646X Institute of Methodologies for Environmental Analysis, CNRIMAA, Italy;

C. da S. Loya, 85050 Tito Scalo, Potenza, Italy

\section{REFERENCES}

Agapiou, A. 2020. Detecting Looting Activity through Earth Observation Multi-Temporal Analysis over the Archaeological Site of Apamea (Syria) during 2011-2012. Journal of Computer Applications in Archaeology, 3(1): 219-237. DOI: https://doi.org/10.5334/jcaa.56

Alva, W. 2001. The destruction, looting and traffic of the archaeological heritage of Peru. In: Brodie, N, Doole, J and Renfrew, C (eds.), Trade in illicit antiquities: the destruction of the world's archaeological heritage. Cambridge: McDonald Institute, pp. 89-96.

Alva Meneses, I. (ed.) 2013. Ventarrón y Collud. Origen y auge de la civilización en la costa norte del Perú. Cercado de Lima: Ministerio de Cultural del Peru/Proyecto Especial Naylamp Lambayeque.

Anselin, L. 1995. Local Indicators of Spatial Association LISA. Geogr Anal, 27: 93-115. DOI: https://doi. org/10.1111/j.1538-4632.1995.tb00338.x

Batievsky, J and Velarde, J. 2006. The protection of cultural patrimony in Peru. In: Hoffmann, BT (ed.), Art and cultural heritage: law, policy, and practice. New York: Cambridge University Press, pp. 100-104.

Brodie, $\mathbf{N}$ and Renfrew, C. 2005. Looting and the 
world's archaeological heritage: The Inadequate Response. Annual Review of Anthropology, 34(1): 343-361. DOI: https://doi.org/10.1146/annurev. anthro.34.081804.120551

Brodie, $\mathbf{N}$ and Yates, D. 2019. Illicit trade in cultural goods in Europe. Characteristics, criminal justice responses and an analysis of the applicability of technologies in the combat against the trade. Luxembourg: Publications Office of the European Union.

Casana, J. 2015. Satellite imagery-based analysis of Archaeological Looting in Syria. Near Eastern Archaeology, 78(3): 142-152. DOI: https://doi.org/10.5615/ neareastarch.78.3.0142

Casana, J and Panahipour, M. 2014. Satellite-Based Monitoring of Looting and Damage to Archaeological Sites in Syria. Journal of Eastern Mediterranean Archaeology and Heritage Studies, 2(2): 128-150. DOI: https://doi.org/10.5325/ jeasmedarcherstu.2.2.0128

Cerra, D, Pank, S, Lysandrou, V and Tian, J. 2016. Cultural Heritage Sites in Danger-Towards Automatic Damage Detection from Space. Remote Sensing, 8(9): 781. DOI: https://doi.org/10.3390/rs8090781

Contreras, DA. 2010. Huaqueros and remote sensing imagery: assessing looting damage in the Viru Valley, Peru. Antiquity, 84(324): 544-555. DOI: https://doi.org/10.1017/ S0003598X0006676X

Doering, HU. 1958. Bericht über archaologische Feldarbeiten in Perú. Ethnos, 23(2-4): 67-99. DOI: https://doi.org/10.1080/0 0141844.1958 .9980850

Eeckhout, P. 1995. Pirámide con rampa No III de Pachacamac, costa central del Perú: resultados preliminares de la primera temporada de excavaciones (zona 1 y 2). Bulletin de l'Institut Français d'Etudes Andines, 24(1): 169-214.

El-Hajj, H. 2021. Interferometric SAR and Machine Learning: Using Open Source Data to Detect Archaeological Looting and Destruction. Journal of Computer Applications in Archaeology, 4(1): 47-62. DOI: https://doi.org/10.5334/ jcaa. 70

Forrest, C. 2010. Craig International Law and the Protection of Cultural Heritage. Routledge.

Gerdau-Radonic, K and Herrera, H. 2010. Why dig looted tombs? Two examples and some answers from Keushu (Ancash highlands, Peru). Bulletins et Memoires de la Societe d'Anthropologie de Paris, 22(3-4): 145-156. DOI: https://doi.org/10.1007/s13219-010-0012-4

Hesse, R. 2010. LiDAR-derived Local Relief Models a new tool for archaeological prospection. Archaeol. Prospect., 17: 67-72. DOI: https://doi.org/10.1002/arp.374

Higueras, A. 2008. Cultural Heritage Management in Peru: Current and Future Challenges. In: Silverman, $\mathrm{H}$ and Isbell, W (eds.), The Handbook of South American Archaeology. Urbana: University of Illinois at Urbana-Champaign, pp. 1073-1088. DOI: https://doi.org/10.1007/978-0-38774907-5_54

Lasaponara, R, Abate, $\mathbf{N}$ and Masini, $\mathbf{N} 2021$. On the Use of Google Earth Engine and Sentinel Data to Detect "Lost"
Sections of Ancient Roads. The Case of Via Appia. IEEE Geoscience and Remote Sensing Letters. DOI: https://doi. org/10.1109/LGRS.2021.3054168

Lasaponara, R, Danese, M and Masini, N. 2012. SatelliteBased Monitoring of Archaeological Looting in Peru. In: Lasaponara, R and Masini, N (eds.), Satellite Remote Sensing: a new tool for Archaeology. Dordrecht: Springer, pp. 177-193. DOI: https://doi.org/10.1007/978-90-481-88017_8

Lasaponara, R, Leucci, G, Masini, N and Persico, R. 2014. Investigating archaeological looting using satellite images and georadar: the experience in Lambayeque in North Peru. Journal of Archaeological Science, 42(2014): 216-230. DOI: https://doi.org/10.1016/j.jas.2013.10.032

Lasaponara, R and Masini, N. 2016. Combating Illegal Excavations in Cahuachi: Ancient Problems and Modern Technologies. In: Lasaponara, R, Masini, N and Orefici, G (eds.), The Ancient Nasca World. New Insights from Science and Archaeology. Cham: Springer, pp. 605-633. DOI: https:// doi.org/10.1007/978-3-319-47052-8_25

Lasaponara, R and Masini, N. 2018. Space-Based Identification of Archaeological Illegal Excavations and a New Automatic Method for Looting Feature Extraction in Desert Areas. Surv Geophys, 39: 1323-1346. DOI: https://doi.org/10.1007/ s10712-018-9480-4

Martorell-Carreño, A. 2006. Cultural Patrimony and Property rights in Peru. In: Hoffmann, BT (ed.), Art and cultural heritage: law, policy, and practice. New York: Cambridge University Press, pp. 105-108.

Netcher, NETwork and digital platform for Cultural Heritage Enhancing and Rebuilding. 2020. https://netcher.eu/.

Orefici, G. 2016. The Ceremonial Center of Cahuachi: its origins and evolution. In: Lasaponara, R, Masini, N and Orefici, G (eds.), The Ancient Nasca World. New Insights from Science and Archaeology. Cham: Springer, pp. 329-342. DOI: https:// doi.org/10.1007/978-3-319-47052-8_14

Proulx, BB. 2013. Archaeological Site Looting in "Glocal" Perspective: Nature, Scope, and Frequency. American Journal of Archaeology, 117 (1): 111-125. DOI: https://doi. org/10.3764/aja.117.1.0111

Ravines, R. 1996. Pachacamac: Santuario Universal. Lima: Editorial Los Pinos E.I.R.L.

Shimada, I. 1991. Pachacamac Archaeology. Retrospect and Prospect. In: Uhle, M and Shimada, I (eds.), Pachacamac. A Reprint of the 1903 Edition. Philadephia: University of Pennsylvania Press.

Silverman, H. 1993. Cahuachi in the Ancient Nasca World. Iowa City: University of Iowa Press.

Stone, EC. 2008. Patterns of looting in southern Iraq. Antiquity, 82: 125-138. DOI: https://doi.org/10.1017/ S0003598X00096496

Tapete, D and Cigna, F. 2019. Detection of Archaeological Looting from Space: Methods, Achievements and Challenges. Remote Sens. 11, 20(2389). DOI: https://doi. org/10.3390/rs11202389

Tapete, D, Cigna, F and Donoghue, DNM. 2016. “Looting 
marks" in space-borne SAR imagery: Measuring rates of archaeological looting in Apamea (Syria) with TerraSAR-X Staring Spotlight. Remote Sens. Environ., 178: 42-58. DOI: https://doi.org/10.1016/j.rse.2016.02.055

Tello, JC. 1929. Antico Peru: primera epoca. Lima: Comision Organizadora del Segundo Congreso Sudamericano de Turismo.

UNESCO. 1970. Convention on the Means of Prohibiting and Preventing the Illicit Import, Export and Transfer of Ownership of Cultural Property.

Van Ess, M, Becker, H, Fassbinder, J, Kiefl, R, Lingenfelder, I, Schreier, $\mathbf{G}$ and Zevenbergen, A. 2006. Detection of
Looting Activities at Archaeological Sites in Iraq Using Ikonos Imagery. Angewandte Geoinformatik, Beitraege zum 18. Heidelberg: Wiechmann-Verlag, pp. 668-678.

Yates, D. 2015. Illicit Cultural Property from Latin America: Looting, Tracking, and Sale. In Illicit Tracking in Latin America. Paris: International Council of Museums, pp. 33-45.

Zakšek, K, Oštir, K and Kokalj, Ž. 2011. Sky-view factor as a relief visualization technique. Remote Sens., 3: 398-415. DOI: https://doi.org/10.3390/rs3020398

TO CITE THIS ARTICLE:

Masini, N and Lasaponara, R. 2021. Remote and Close Range Sensing for the Automatic Identification and Characterization of Archaeological Looting. The Case of Peru. Journal of Computer Applications in Archaeology, 4(1), 126-144. DOI: https://doi.org/10.5334/ jcaa.73

Submitted: 18 March 2021 Accepted: 23 March 2021 Published: 09 June 2021

\section{COPYRIGHT:}

(c) 2021 The Author(s). This is an open-access article distributed under the terms of the Creative Commons Attribution 4.0 International License (CC-BY 4.0), which permits unrestricted use, distribution, and reproduction in any medium, provided the original author and source are credited. See http://creativecommons.org/licenses/by/4.0/.

Journal of Computer Applications in Archaeology is a peer-reviewed open access journal published by Ubiquity Press.

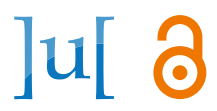

